\title{
BMJ Open Process evaluation of team-based care in people aged $>65$ years with type 2 diabetes mellitus
}

\author{
Joanie Sims Gould, ${ }^{\oplus 1,2}$ Catherine Tong, ${ }^{1}$ Jessica Ly, ${ }^{1}$ Sara Vazirian, \\ Adriaan Windt, ${ }^{1}$ Karim Khan $^{1,2}$
}

To cite: Sims Gould J, Tong C, Ly J, et al. Process evaluation of team-based care in people aged $>65$ years with type 2 diabetes mellitus. BMJ Open 2019;9:e029965. doi:10.1136/ bmjopen-2019-029965

- Prepublication history for this paper is available online. To view these files, please visit the journal online (http://dx.doi org/10.1136/bmjopen-2019029965).

Received 21 February 2019 Revised 20 June 2019 Accepted 24 June 2019
Check for updates

(C) Author(s) (or their employer(s)) 2019. Re-use permitted under CC BY-NC. No commercial re-use. See rights and permissions. Published by BMJ.

${ }^{1}$ Centre for Hip Health and Mobility, University of British Columbia, Vancouver, British Columbia, Canada

${ }^{2}$ Department of Family Practice, University of British Columbia, Vancouver, British Columbia, Canada

Correspondence to Dr Joanie Sims Gould simsg@mail.ubc.ca

\section{ABSTRACT}

Objective The prevalence of type 2 diabetes mellitus (T2DM) is increasing globally and there is critical need develop interventions to improve health outcomes among older people. The Group Appointments in Primary Care (GAP) study was a randomised controlled trial designed to test the efficacy of a group and team-based medical visit programme to lower haemoglobin A1C among patients with T2DM. We aimed to understand the barriers and facilitators to implement the GAP intervention within a primary care setting, with an emphasis on patient experience.

Research design and methods This was a qualitative exploratory study. Data were gathered from semistructured interviews conducted with the first cohort of GAP study participants $(n=15)$ at baseline and intervention completion. GAP participants were aged $>65$, diagnosed with T2DM and from one primary care clinic. The interview questions identified the patient perspectives and factors relating to their attendance at seven group medical visits that were part of the intervention programme. Data were analysed using framework analysis.

Results We identified four themes that captured participants' experiences: (1) Education: learning with professionals, learning with one another; (2) Social Support: common interests, common problems; (3) Setting: ease of location, ease of conversation and (4) Impact: expectations met, empowerment gained. The GAP intervention increased participants' self-reported diabetes literacy and self-management skills.

Conclusions We learnt that: accessible community centres, not primary care offices, were the ideal location for GAP; the consistent leadership of the primary care physician was valued by participants; and, the content related to exercise and healthy diet were viewed as impactful. Also, learning was achieved through content delivered by clinical experts, and by T2DM experts with lived experience - the GAP peers. Our findings highlight the important role of group learning.

Trial registration number NCT02002143

\section{INTRODUCTION}

In North America, the population of older adults ( $>65$ years) is projected to double over the next 25 years. ${ }^{1}$ The most rapidly growing segment of North America's population are those over age $85^{2}$ and the rate of type 2

\section{Strengths and limitations of this study}

- We conducted a process evaluation of the first randomised controlled trial (RCT) to evaluate group medical visits with a general practitioner lead in diabetes management.

- Through in-depth interviews, we identified strengths of the group medical visit approach and highlighted the important role of group learning.

- Findings suggest that primary care physician-led team-based care can engage patients, help them better understand type 2 diabetes mellitus and its management.

- Currently, the study is limited to one geographical location with a relatively homogeneous population. Given that a single specific physician is leading the intervention, the findings may not be generalisable to other practitioners.

- This analysis was limited to the first cohort $(\mathrm{N}=15)$ of the Group Appointments in Primary Care study RCT.

diabetes mellitus (T2DM) among adults $\geq 65$ years exceeds $20 \% .^{3}$ Rates of T2DM in older people are accelerating even when adjusted for age. ${ }^{45}$ Therefore, T2DM and management is an established priority within primary care.

Good metabolic control of diabetes prevents complications. ${ }^{67}$ Combinations of drug treatment, physical activity (PA), ${ }^{8}$ nutrition advice and body weight management ${ }^{910}$ reduce risk factors, delay onset of disease and lessen the rate of complications. ${ }^{611-13}$ Lifestyle interventions focused on bodyweight control, PA and dietary modification can prevent or postpone the manifestation of type 2 diabetes. ${ }^{14}$

One-to-one clinical encounters will always have a place in health service delivery, but there is also compelling clinical trial data ${ }^{15-17}$ that group medical visits (GMVs) have the potential to improve diabetes management and outcomes. GMVs in primary care increase patient and physician satisfaction, deliver integrated and quality care, improve patient access and leverage physician time 
and productivity. ${ }^{18}{ }^{19}$ Group appointments can serve people who live with a specific condition (eg, T2DM) and conveniently provide interprofessional team care to the patient group. ${ }^{19}$ The structure and formats of GMVs vary; typically, in lieu of an individual visit, a patient will participate in a longer group visit with 6-14 other patients, led by a physician who often works with an interprofessional healthcare team.

We conducted a qualitative process evaluation of the randomised controlled trial (RCT) of team-based care. The protocol for that now-completed study is reported elsewhere. ${ }^{20}$ That RCT aimed to determine the clinical effectiveness, quality of life and economic implications of primary care-led team-based care for older people with T2DM.

Our process evaluations of this RCT examined how group visits were delivered and how patients/study participants responded to them ${ }^{21} 22$; process evaluations can assess the feasibility of scale up and potential transferability of such interventions. Process evaluation can be used to: examine patient experiences of an RCT, capture how the intervention was delivered and investigate contextual factors related to the delivery of the intervention. ${ }^{21}$ Reviewing the patients' experiences of the intervention can inform how researchers interpret the study outcomes. ${ }^{23}$ We undertook a process evaluation of the Group Appointments in Primary Care (GAP) trial to identify whether the intervention could be expanded and to assess the quality of the intervention and the mode of delivery.

\section{RESEARCH DESIGN AND METHODS Overview of the GAP RCT}

The GAP RCT is a proof-of-concept, single-blinded (measurement team) RCT testing the efficacy of GMVs in a primary care setting. Participants are 65 years or older with T2DM ( $\mathrm{N}=97)$ and randomised to either (A) GMVs over a 24-month period led by a primary care physician (intervention, $\mathrm{N}=49$ ) or (B) traditional one-to-one usual care appointments also provided by a primary care physician (control, $\mathrm{N}=48$ ). Participants were recruited from one clinic in a single urban setting in British Columbia, Canada.

The intervention uses a chronic care model ${ }^{24-26}$ by combining an interprofessional team-based medical care, patient self-management, life skills development and disease-specific education, with a focus on PA and nutrition. The chronic care model ${ }^{24-26}$ is a primary care model that emphasises self-management of chronic diseases, guided by an interprofessional team. Interventions using the chronic care model reduce healthcare costs, lower the use of healthcare services and improve at least one outcome measure for patients with diabetes. ${ }^{26}$ The content of the intervention is based on the successful Trento model, ${ }^{19} 2728$ with an additional focus using our research team's expertise from 10 years of PA interventions. The GAP intervention was composed of seven
GMVs over 24 months as well as usual care, delivered through one-on-one physician appointments. GMVs were educational seminars targeted to a specific aspect of T2DM; the primary objective of the GMVs was to provide patients with skills for T2DM self-management. Seminar topics included: PA, three sessions on diet and healthy eating, complications of diabetes, monitoring of diabetes and diabetes medication. One primary care physician was present at all GMVs, in addition a pharmacist, exercise professional and nutritionist who served as guest speakers. Sessions consist of 'clinical time' and 'group education/discussion time'. In the clinical time, the physician responded to specific health questions from patients. Patients were also given a FitBit wireless activity tracker which was intended to serve as an additional motivational tool.

The GMVs were organised by a research coordinator and cofacilitated by a physician and either an exercise specialist, nutritionist or pharmacist, depending on the session topic. Each GMV was separated into three sections: (1) introduction/summary of previous session content, (2) educational component and (3) goal setting and feedback. GMVs were held on Friday afternoons, every 3 months, at a local recreation complex. The control arm received their usual care, through traditional one-on-one physician appointments. The GMVs were conducted with five cohorts, averaging 19 participants per cohort (total $\mathrm{N}=97$ ), over a 4-year period. For more information on the GAP trial, see ref 20.

\section{Process evaluation design and methods}

As an extension of the larger GAP RCT, we undertook a process evaluation to capture patients' perspectives on the content, delivery and impact of the GMVs. This was a qualitative exploratory study, in which we employed a 'generic' ${ }^{29}$ or 'non-categorical' qualitative research approach. We principally report on the follow-up interviews with participants, on completion of the intervention.

\section{Participants and setting}

Participants were recruited from the first cohort of patients $(\mathrm{N}=17)$ that completed the intervention arm of the GAP RCT. These participants were older adults, over the age of 65, diagnosed with T2DM, live in British Columbia (Canada), and attend the clinic associated with the RCT. We mailed participants from the first cohort a letter detailing the process evaluation, interview, and a consent form. Of the 17 participants in the first cohort, 15 ( 6 women and 9 men with a mean age of 73 ) completed an evaluation interview.

\section{Data collection}

A trained master's level research assistant, who was not directly involved in the implementation of the GMVs, conducted semistructured telephone interviews at the outset of the GAP study and at its completion. The interviewer was a woman who had no prior relationship or contact with the participants; the interviewer 
was trained by the lead author and had prior experience conducting in-depth interviews with older adults. Initial interviews (T1) were 10-20 mins, and the more in-depth follow-up interviews (T2) averaged $90 \mathrm{~min}$ (range: 45-120 $\mathrm{min}$ ). The follow-up interviews were more in-depth, and as such form the bulk of the results presented here in this exploratory analysis. Interviews were digitally recorded. The coinvestigators leading the GAP trial developed the interview guide. The T1 interviews asked participants about their expectations and goals for the GMVs, and the T2 interviews sought to answer the following:

1. How did participants experience the recruitment process into the GAP RCT study?

2. What were patients' expectations before and after participating, and did they differ?

3. How did participants feel about the planning and logistics of the group appointment to deliver team-based care?

4. How did the participants receive the material that was delivered?

5. How did GMVs compare to the diabetes care that they received in traditional medical appointments?

6. What has been the impact of the GMVs on how patients self-manage their T2DM?

7. Are there any aspects of the GMVs that could be improved?

\section{Data analysis}

Interview recordings were transcribed verbatim by a professional transcriptionist. Data were deidentified, participants were assigned the pseudonyms used here, and imported to NVivo V.11 (QSR International, 2015) for data analysis. Interview data were analysed using framework analysis, ${ }^{30}{ }^{31}$ an appropriate analytical approach for qualitative studies with specific questions, a predesigned sample, and a priori issues identified. ${ }^{30}$ Coders all had master's degrees or PhDs, were not present at any of the GMVs, and had extensive prior experience with qualitative data analysis and research with older adults. Two team members (JSG and SV) sorted data and initially created a broad coding framework aligned with the aim of each interview question. During a second cycle of coding, two team members (CT and JL) applied a focused coding procedure to the broad coding framework. As a team, the coauthors agreed that saturation had been reached in the fifteen interviews. ${ }^{32}$

\section{Patient and public involvement}

By engaging with patients from the first cohort, one objective of this process evaluation was to use their perspectives on the GMVs to inform the implementation of the remainder of the RCT, including any feedback on patient burden. This was an intentional effort to formally capture, and apply, patient perspectives and experiences at the outset of the trial. Patients were not involved in the identification of the research question, outcome measures or recruitment. Patients and other stakeholders were provided with a plain language report summarising the results of this study and were invited to provide feedback.

\section{RESULTS}

We identified four themes that captured participants' experiences of the GAP Trial: (1) Education: learning with professionals, learning with one another; (2) Social Support: common interests, common problems; (3) Setting: ease of location, ease of conversation and (4) Impact: expectations met, empowerment gained. Having an interdisciplinary team specialised in diabetes care provided participants with a more comprehensive education about T2DM. The group setting was also important for participants, being able to discuss their problems and see that others were experiencing the same thing was beneficial to their engagement. This setting also led to discussions and questions that would not have arisen in a one-to-one visit with their primary care provider. The GMVs increased participants' diabetes literacy and self-management skills.

\section{Education: learning with professionals, learning with one another \\ Topics and information}

All participants reported an increased level of diabetes literacy following the GMVs. One important factor that was highlighted was the presenters' skills and their attitude, as well as the informative and non-repetitive topics that were discussed. Participants commented on how knowledgeable each presenter was and how current the content was.

[The doctor] was the most eloquent of the people I have talked to in describing the mechanics of diabetes. So that gave me a greater understanding of the difference that exercise makes in an actual demonstrable way. (Patrick, 69, T2)

The topic most appreciated by participants was diet and healthy eating. All topics covered were considered very practical to diabetes care. The information on the handouts that was provided was easy to understand and review, however, there were many requests for a more comprehensive booklet to be provided at the end of the study. The PowerPoint presentations were described by patients as beneficial and engaging. The design and facilitation made it easy for them to follow along with the topics being discussed. The delivery format of the GMV seemed to be an important factor in comprehension and education retention:

Well, I think it's-a doctor's more prescriptive. Do this, do-whereas in the medical [...] with a group it's a lot more informal and you learn, you know, what to do and what to avoid far better than with a doctor, I guess. (William, 76, T2)

Overall, the content delivered in the GMVs for chronic care management was very well received. The group 
experience proved to be beneficial in providing a broader scope of education for diabetes management rather than just singular discussions that take place in standard care with a primary care provider. Having presenters experienced in their specific fields about diabetes management provided the participants with improved diabetes literacy and self-management skills. The participants could not suggest any other topics to be considered on their own.

\section{Social support: common interests, common problems}

Although the participants were all recruited from the same clinic, they did not know one another prior to the GMVs. All 15 participants described the opportunity of meeting new people and expanding their social network as 'exciting'.

An overarching theme in the interviews was the important influence the group setting dynamic had for each participant in receiving and engaging in dialogue about diabetes management. The informal setting of the GMVs allowed for participants to feel comfortable and open to asking questions, not only of the presenter, but of other participants in the group. This openness facilitated discussions about current care, struggles, successes, concerns and questions that participants would or could not have spoken openly about otherwise. Being able to meet and talk to people who were experiencing the same thing that they were going through was very important.

With the group you can contemplate the next thing that you're going to talk about and you're not, like, when you go to the doctor you have an appointment and if you don't bring up what's important, he doesn't know what's important. You have to bring it up and I always forget. So when we're the group they bring up stuff that I wanted to bring up but I hadn't had-hadn't brought it along in my brain. And it makes a difference and I think I personally need both. (Beverly, 76, T2)

It's nice when we get a chance to discuss common interests and common problems. So if there's something that, you know, we all struggle with it's really good to know that other people are having the same issue. (Evelyn, 73, T2)

\section{GMVs versus traditional one-on-one physician appointments}

Unlike traditional physician appointments, GMVs deliver diseases management education and strategies in a social setting. Participants reported the advantages and disadvantages of GMVs versus individual medical appointments (see table 1). One participant noted that some people tended to dominate and take over the discussion, but this occurs in any group setting and was tactically mitigated by the care team. No participants had previously participated in a GMV.

\section{Setting: ease of location, ease of conversation}

The sessions were held at a local recreation complex on Friday afternoons. The complex was easily accessible (ground floor), served by local public transit routes, with
Table 1 Comparison of group medical visits and individual medical appointments

\section{Advantages of group medical visits \\ Disadvantages of group medical visits}

Being in a group setting of people who have similar health challenge

Having an opportunity to learn from each other's experience

- Having more time to ask questions of the physician

- Concerns of diabetes were better addressed

\begin{tabular}{lc}
\hline $\begin{array}{l}\text { Advantages of individual } \\
\text { medical appointments }\end{array}$ & $\begin{array}{l}\text { Disadvantages of individual } \\
\text { medical appointments }\end{array}$ \\
\hline $\begin{array}{l}\text { Seeing your own } \\
\text { personal family doctor }\end{array}$ & $\begin{array}{l}\text { Not enough time to discuss } \\
\text { individual problems }\end{array}$ \\
Family doctor knows & \\
patient history & \\
\hline
\end{tabular}

ample-free parking available. The room set-up, a group of chairs in a U-shape facing a screen and the presenter, was conducive to group discussions. Patients described the atmosphere very welcoming and felt at ease. The sessions were reported as stimulating and informative with no pressure into talking or any type of criticism for sharing their views.

It's a central location for most people, I think, and the room is big enough and it's a nice place to be anyway, the rec centre. (Richard, 70, T2)

There's more information flying around vs on a one-on-one basis. A question's put out and answers come back that you would never have even thought of. It's a place to share and hear other people's opinions. (Mary, 70, T2)

\section{Impact: expectations met, empowerment gained}

Participant expectations were identified at the outset of the study in the T1 interviews. The expectations and hopes participants identified for the GMVs are outlined in box 1. Participant expectations centred on diabetes education. Speaking retrospectively about his hopes and expectations for the programme, Robert recounted:

I guess I was hoping to get maybe a better understanding about diabetes for one thing. And I guess I've had it probably 10 years, so-I thought it would be a good thing to do. (Robert, 87, T2)

Patient expectations were revisited after the study, in T2 interviews, to see if they had been met. All participants felt that the GMV experience met their initial expectations and identified the social component as an unexpected benefit to participating (Box 1). 


\section{Box 1 Patient expectations and impact}

Patient expectations (identified in T1)

- Improving their health.

- Being able to delay or stop the progress of the disease.

- Better understanding of diabetes.

- Becoming more confident in self-management of their illness.

- How to prevent diabetic complications.

- Helping others and being part of an exciting research study.

- Experiencing a group medical visit (GMV).

Reported impacts of the GMVs (identified in T2).

Impact on levels of physical activity (PA)

- Useful, simple techniques were inspiring and motivating.

- Encouraged patients to be more mindful of adding PA to their daily routines.

- Increased PA levels, assessed with their Fitbit and self-monitoring.

Impact on diet

- Nutritional information provided was easy to understand.

- Nutritional recommendation provided was easy to follow.

- Some patients had dietary restrictions but did not impact ability.

Impact on social/mental and emotional well-being

- Able to discuss common problems in a group setting.

- Opportunity to bond with their group mates and do things together.

- One patient reported feeling more worried due to better understanding about type 2 diabetes mellitus (T2DM).

- One patient reported feeling emotionally stronger and had improved outlook due to better understanding about T2DM.

Empowered to self-care and self-manage

When asked if the improvement in her T2DM symptoms was a result of the content presented at the sessions, one of the participants stated:

Actually, a lot of it had to do with the group talking together and finding out what they've been doing and how they've been doing things and just modifying my things that I'm doing and that seems to be beneficial for me. (Harriet, 76, T2)

All participants reported that the GMV experience provided them with a better understanding of diabetes which enabled them to become more confident in their ability to improve their health. Roy noted that the education sessions motivated him to better monitor his diet and pay more attention to his PA levels:

So far I think everything is sort of falling in place. I see a lot more benefits than if I hadn't been part of the program. I think I'd be still set in my old ways, not doing certain things, not doing the exercise, not paying attention to problems that might happen in the future. Certainly, the diet aspect has helped. So I think, really, everything that's happened so far in the program, I really enjoy. And I hope we get more. (Roy, 74, T2)

The knowledge that they have gained from being in the programme has improved their self-confidence and ability to manage their T2DM on their own. PA has been shown to be beneficial for glycaemic control in patients with $\mathrm{T}_{2} \mathrm{DM}^{33} 34$ so the first GMV is focused on PA. Participants noted that the delivery of PA exercises was presented in such a way that is easily incorporated into their daily lives without the pressure that often comes with intense exercise plans. The three nutrition sessions were identified as the most useful topics covered and were easy to understand and follow.

I'm inspired to go home and, you know, continue on watching my weight and doing my exercise andyeah, just making sure I'm on the right path [...] I think it's just that something is being done, something is being, you know, trying to make improvements on our care and to make our lives better and more rewarding by giving us the information we need to live a good life as a diabetic. (Elizabeth, 71, T2)

The participants reported that the tools the interdisciplinary team shared made their diabetes seem more manageable and provided a more positive outlook on their condition. Several participants reported feeling emotionally stronger because of their increased knowledge about diabetes and have lessened feelings of guilt if they did not follow certain recommendations. ${ }^{35} 36$ This insight is important in addressing concerns around patient adherence to treatment and improved outcomes.

\section{CONCLUSIONS}

In this exploratory process evaluation, we sought to capture patient participants' perspectives on the content, delivery and impact of the GMVs. Through this evaluation, we gleaned several key takeaways regarding the delivery of GMVs for older patients with T2DM. Delivering the GMVs at a centrally located community centre was important to participants, who were familiar with the space and found it easy to access with either public transit or with ample free parking. The set-up of the room allowed for easy group discussion, and participants found the sessions to well led and appropriately facilitated. The GMV topics were well received by the participants, in particular the sessions on healthy eating and diet.

The use of an interdisciplinary care team for chronic disease management is effective ${ }^{3738}$ and our process evaluation helped to identify the following factors that were integral to a successful care programme: a dedicated lead physician present to facilitate the GMVs and discussion among patients and the specialists was key. In addition to having clinical expertise, the physician was consistent, present at each GMV, which is important for trust and relationship-building among learners. ${ }^{39} \mathrm{~A}$ full-time coordinator was necessary for the planning and logistics of the intervention. Process evaluations of RCTS can be used to identify limitations, areas of improvement and determine why trials 'fail', ${ }^{21}$ however, the results of our process evaluation where emphatically positive. Participants consistently described the strengths and benefits of the GMVs. Results of the GAP trial will be published in forthcoming manuscripts. 
In relation to the chronic care model ${ }^{26}$ participants principally referenced the first component: self-management support. Through the GMVs, participants reported new knowledge in three areas: PA, diet and overall wellbeing. Our findings extend existing literature on GMVs highlighting improvements in patient knowledge and self-management. ${ }^{19}$

While participants expected to gain diabetes education at the outset of the study, an unanticipated impact on the value added by the social nature of the groups. Learning was achieved through content delivered by clinical experts, and by T2DM experts with lived experience $^{40}$ - the patients themselves, the GMV peers. Our findings highlight the important role of group learning in the context of chronic care management. While older adults have a range of preferred learning styles, ${ }^{41}$ groupbased learning may be particularly beneficial for individuals managing a disease that carries some stigma, such as T2DM. ${ }^{42}$ There was social support and a sense of solidarity within the group, knowing that everyone was 'in the same boat', managing the same complex chronic condition.

\section{Limitations and future research}

This study is limited to a small homogeneous population from a clinical setting in one location in Western Canada, and in this analysis, we have not reported on the quantitative outcomes of the RCT. The findings may not be generalisable to other regions, settings or populations; however, our findings suggest that primary care physician-led teambased care can engage patients, help them better understand T2DM and its management. Future studies should focus on patients' diabetes literacy to assess how information can be disseminated at earlier stages (eg, patients with prediabetes), with the goal or prevention or delay of onset.

[...] I'm quite pleased with all the information we've gotten. The thing is I wish they would have had this 20 years ago, I wouldn't be on medication...I still say that these studies should be presented to people who are-when they become borderline, that they should get the facts straight and that they can, with diet, control very, very, possibly control it, even get off being a borderline. (George, 79, T2)

In conclusion, if we are to shift the trajectory away from increased chronic disease and associated complications, new strategies are needed. We also need to ensure that we undertake appropriate process evaluations to provide insight into how best to generate, implement and adapt such strategies.

Acknowledgements We acknowledge the contributions of Sheralyn Windt who assisted with data collection.

Contributors JSG had full access to all of the data in the study and takes responsibility for the integrity of the data and the accuracy of the data analysis. Concept and design: JSG, AW and KK. Acquisition of subjects and data: JSG, AW and KK. Data analysis and interpretation: JSG, CT, JL and SV. Preparation of manuscript: JSG, JL and SV. Review and revision of manuscript: JSG, CT, AW and KK.
Funding Funding for this research was provided by British Columbia Ministry of Health and the University of British Columbia Endowment Fund. JSG is support by a Canadian Institutes of Health Research New Investigator award and a Michael Smith Foundation for Health Research Scholar award.

Competing interests None declared.

Patient consent for publication Not required.

Ethics approval We received approval from the University of British Columbia's Behavioural Research Ethics Board (H18-02765).

Provenance and peer review Not commissioned; externally peer reviewed.

Data availability statement Data are available upon reasonable request.

Open access This is an open access article distributed in accordance with the Creative Commons Attribution Non Commercial (CC BY-NC 4.0) license, which permits others to distribute, remix, adapt, build upon this work non-commercially, and license their derivative works on different terms, provided the original work is properly cited, appropriate credit is given, any changes made indicated, and the use is non-commercial. See: http://creativecommons.org/licenses/by-nc/4.0/.

\section{REFERENCES}

1. Statistics Canada. Canada year book. Ottawa, ON: Statistics Canada, 2018.

2. 2 Statistics Canada. A portrait of the population aged 85 and older in 2016 in Canada. Ottawa, ON: Statistics Canada, 2018.

3. Public Health Agency of Canada. Diabetes in Canada: facts and figures from a public health perspective. Ottawa, on: government of Canadafrom. Available: https://www.canada.ca/en/public-health/ services/chronic-diseases/reports-publications/diabetes/diabetescanada-facts-figures-a-public-health-perspective.html [Accessed June 2018].

4. Meneilly GS. Diabetes in the elderly. In: JE M, ed. Medical clinics of North America-geriatric medicine. Philadelphia, PA: Elsevier Saunders, 2006: 90. 909-23.

5. Doucet G, Beatty M. The cost of diabetes in Canada: the economic tsunami. Can J Diabetes 2010;34:27-9.

6. Knowler WC. Prevention of type 2 diabetes: comment on "Lifestyle modification and prevention of type 2 diabetes in overweight Japanese with impaired fasting glucose levels". Arch Intern Med 2011;171:1361-2.

7. Steinsbekk A, Rygg L, Lisulo M, et al. Group based diabetes selfmanagement education compared to routine treatment for people with type 2 diabetes mellitus. A systematic review with metaanalysis. BMC Health Serv Res 2012;12:213.

8. Umpierre D, Ribeiro PAB, Schaan BD, et al. Volume of supervised exercise training impacts glycaemic control in patients with type 2 diabetes: a systematic review with meta-regression analysis. Diabetologia 2013;56:242-51.

9. Ferchak CV, Meneghini LF, Obesity ML. Obesity, bariatric surgery and type 2 diabetes?a systematic review. Diabetes Metab Res Rev 2004;20:438-45.

10. Staimez L, Weber M, Narayan K, et al. A systematic review of overweight, obesity, and type 2 diabetes among Asian American subgroups. Curr Diabetes Rev 2013;9:312-31.

11. Knowler WC, Barrett-Connor E, Fowler SE, et al. Reduction in the incidence of type 2 diabetes with lifestyle intervention or metformin. N Engl J Med 2002;346:393-403.

12. Buehler AM, Cavalcanti AB, Berwanger O, et al. Effect of tight blood glucose control versus conventional control in patients with type 2 diabetes mellitus: a systematic review with meta-analysis of randomized controlled trials. Cardiovasc Ther 2013;31:147-60.

13. Al Sayah F, Williams B, Johnson JA. Measuring health literacy in individuals with diabetes: a systematic review and evaluation of available measures. Health Educ Behav 2013;40:42-55.

14. Lindström J, llanne-Parikka P, Peltonen $M$, et al. Sustained reduction in the incidence of type 2 diabetes by lifestyle intervention: follow-up of the Finnish diabetes prevention study. The Lancet 2006;368:1673-9.

15. Cauch-Dudek K, Victor JC, Sigmond M, et al. Disparities in attendance at diabetes self-management education programs after diagnosis in Ontario, Canada: a cohort study. BMC Public Health 2013;13:85.

16. Sanz C, Gautier J-F, Hanaire H. Physical exercise for the prevention and treatment of type 2 diabetes. Diabetes Metab 2010;36:346-51.

17. Alexander GC, Sehgal NL, Moloney RM, et al. National trends in treatment of type 2 diabetes mellitus, 1994-2007. Arch Intern Med 2008;168:2088-94. 
18. Housden L, Wong ST, Dawes M. Effectiveness of group medical visits for improving diabetes care: a systematic review and metaanalysis. Can Med Assoc J 2013;185:E635-E644.

19. Trento M, Passera P, Tomalino M, et al. Group visits improve metabolic control in type 2 diabetes: a 2-year follow-up. Diabetes Care 2001;24:995-1000.

20. Khan KM, Windt A, Davis JC, et al. Group medical visits (GMVs) in primary care: an RCT of group-based versus individual appointments to reduce HbA1c in older people. BMJ Open 2015;5:e007441-10.

21. Oakley A, Strange V, Bonell C, et al. Process evaluation in randomised controlled trials of complex interventions. BMJ 2006;332:413-6.

22. Craig P, Dieppe P, Macintyre S, et al. Developing and evaluating complex interventions: the new medical Research Council guidance. BMJ 2008;337:a1655-61.

23. Moore GF, Audrey S, Barker M, et al. Process evaluation of complex interventions: medical research council guidance. BMJ 2015;350:h1258-65.

24. Bodenheimer Tet al. Patient self-management of chronic disease in primary care. JAMA 2002;288:2469-75.

25. Bodenheimer T, Wagner EH, Grumbach K. Improving primary care for patients with chronic illness. JAMA 2002;288:1775-9.

26. Bodenheimer T, Wagner EH, Grumbach K. Improving primary care for patients with chronic illness: the chronic care model, part 2. JAMA 2002;288:1909-14.

27. Trento M, Gamba S, Gentile L, et al. Rethink organization to iMprove education and outcomes (ROMEO): a multicenter randomized trial of lifestyle intervention by group care to manage type 2 diabetes. Diabetes Care 2010;33:745-7.

28. Trento M, Passera P, Borgo E, et al. A 5-year randomized controlled study of learning, problem solving ability, and quality of life modifications in people with type 2 diabetes managed by group care. Diabetes Care 2004;27:670-5.

29. Caelli K, Ray L, Mill J. 'Clear as mud': toward greater clarity in generic qualitative research. International Journal of Qualitative Methods 2003;2:1-13.
30. Srivastava A, Thomson SB. Framework analysis: a qualitative methodology for applied policy research. J Admin Governance 2009;72:1-8.

31. Gale NK, Heath G, Cameron E, et al. Using the framework method for the analysis of qualitative data in multi-disciplinary health research. BMC Med Res Methodol 2013;13:117-25.

32. Morse JM. The significance of saturation. Thousand Oaks, CA: Sage Publications, 1995: 147-9.

33. Warburton DER, Nicol CW, Bredin SS. Health benefits of physical activity: the evidence. Can Med Assoc J 2006;174:801-9.

34. Tuomilehto J, Lindström J, Eriksson JG, et al. Prevention of type 2 diabetes mellitus by changes in lifestyle among subjects with impaired glucose tolerance. N Engl J Med 2001;344:1343-50.

35. Delahanty LM, Grant RW, Wittenberg E, et al. Association of diabetes-related emotional distress with diabetes treatment in primary care patients with Type 2 diabetes. Diabet Med 2007;24:48-54.

36. Polonsky WH, Anderson BJ, Lohrer PA, et al. Assessment of diabetes-related distress. Diabetes Care 1995;18:754-60.

37. Litaker D, Mion LC, Planavsky L, et al. Physician-nurse practitioner teams in chronic disease management: the impact on costs, clinical effectiveness, and patients' perception of care. J Interprof Care 2003;17:223-37.

38. Grumbach K, Bodenheimer T. Can health care teams improve primary care practice? JAMA 2004;291:1246-51.

39. Emery MJ. Effectiveness of the clinical instructor: students' perspective. Phys Ther 1984;64:1079-83.

40. George SR, Thomas SP. Lived experience of diabetes among older, rural people. J Adv Nurs 2010;66:1092-100.

41. Truluck E, Bradley C, Courtenay J. Learning style preferences among older adults. Educ Gerontol 1999;25:221-36.

42. Browne JL, Ventura A, Mosely K, et al. 'I call it the blame and shame disease': a qualitative study about perceptions of social stigma surrounding type 2 diabetes. BMJ Open 2013;3:e003384-10. 